\title{
The Evolutionary Basis of Rigidity: Locks in Cells, Minds, and Society
}

\author{
$\underline{\text { Marten Scheffer }}^{1}$ and Frances R. Westley $^{2}$
}

\begin{abstract}
Feedbacks leading to alternative stable modes of behavior occur on levels varying from the cell and the mind to societies. The tendency to lock into a certain pattern comes at the cost of the ability to adjust to new situations. The resulting rigidity limits the ability of persons, groups, and companies to respond to new problems, and some even suggest that it may have contributed to the collapse of ancient societies. In the face of these negative effects, it may seem surprising that lock-in situations are so ubiquitous. Here, we show that the tendency to lock into one of several alternative modes usually serves an apparent purpose. In cells, it filters out noise, and allows a well-defined and consistent behavior once a certain threshold is passed. Basically, the same holds for the attitudes and behavior of individuals and groups. This functionality is not surprising as it has evolved through selection for fitness. Understanding why rigidity makes sense may help in finding ways to avoid traps in situations where flexible response and innovation are needed.
\end{abstract}

Key Words: adaptive capacity in humans

\section{THE THEORY OF LOCKS AND CRITICAL TRANSITIONS}

Although systems may respond to changes in their environment smoothly (Fig. 1a), they are often rather insensitive over certain ranges of the external conditions, although responding relatively strongly around some threshold condition (Fig. 1b). For instance, the survival of an organism usually drops sharply around some critical concentration of a toxicant. A crucially different situation arises when the response curve is "folded" backward (Fig. 1c). Such a "catastrophe fold" implies that, for certain environmental conditions, the system has two alternative equilibria, separated by an unstable equilibrium (dashed) that marks the border between the basins of attraction of the alternative stable states.

This has profound implications for the response to environmental change (Fig. 2a). When the system is in a state on the upper branch of the folded curve, it cannot pass to the lower branch smoothly. Instead, when conditions change sufficiently to pass the threshold (F2), a "catastrophic" transition to the lower branch occurs. Note that, if one monitors the system on a stable branch before a switch, little change in its state is observed. Indeed, such catastrophic shifts occur typically quite unannounced, and "early warning signals" of approaching catastrophic change are difficult to obtain. An important feature of systems with alternative stable states is that, in order to induce a switch back to the upper branch, it is not sufficient to restore the environmental conditions existing before the collapse (F2). Instead, one must go back further, beyond the other switch point $(\mathrm{F} 1)$, where the system recovers by shifting back to the upper branch. This pattern, in which the forward and backward switches occur at different critical conditions (Fig. 2 a), is known as hysteresis (Scheffer et al. 2001, Strogatz 1994).

Everyday examples of systems with such properties are well known. For instance, the slowly increasing pressure of a finger may eventually flip a switch and abruptly turn on a light. Hysteresis occurs, because reducing the pressure to levels occurring before the switch was flipped will not switch the light off again. Similarly, gradually leaning further and further over to one side of a canoe may bring the boat to a critical tipping point. It will capsize and end up in an 
Fig. 1. Schematic representation of possible ways in which the equilibrium state of a system can vary with conditions, such as nutrient loading, exploitation, or a rise in temperature. In panels a and b, only one equilibrium exists for each condition. However, if the equilibrium curve is folded backward (panel c), three equilibria can exist for a given condition. The arrows in the graphs indicate the direction in which the system moves if it is not in equilibrium (i.e., not on the curve). It can be seen from these arrows that all curves represent stable equilibria, except for the dashed middle section in panel c. If the system is pushed away a little bit from this part of the curve, it will move further away instead of returning. Hence, equilibria on this part of the curve are unstable and represent the border between the basins of attraction of the two alternative stable states on the upper and lower branches.

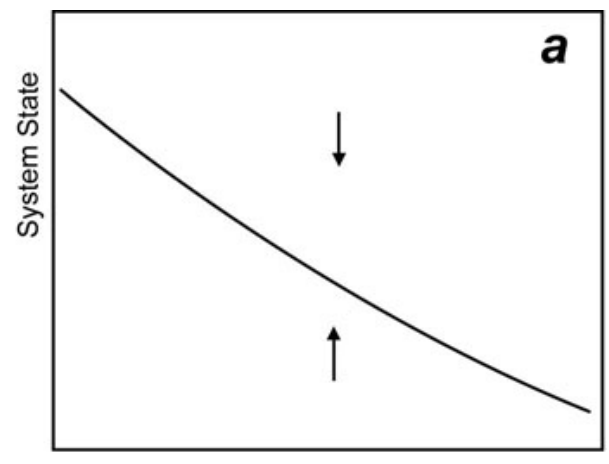

Conditions

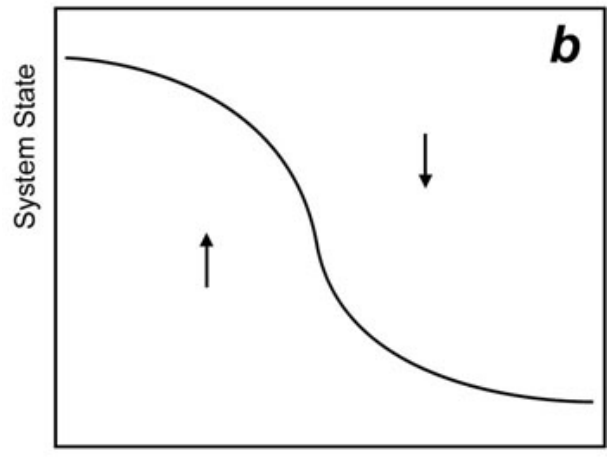

Conditions

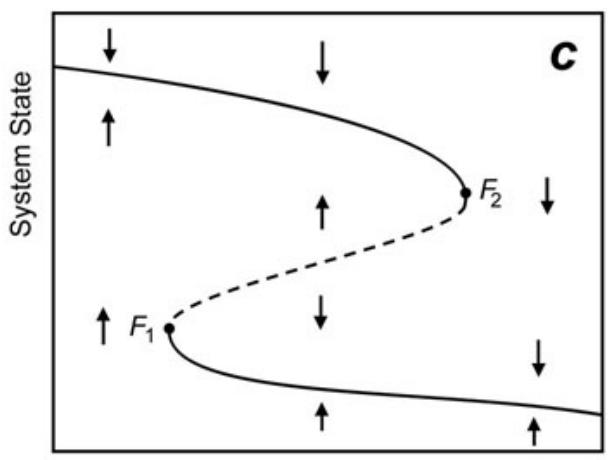

Conditions 
Fig. 2. Two ways to shift between alternative stable states. (a) If the system is on the upper branch, but close to the bifurcation point F2, a slight incremental change in conditions may bring it beyond the bifurcation and induce a catastrophic shift to the lower alternative stable state ("forward shift"). If one tries to restore the state on the upper branch by means of reversing the conditions, the system shows hysteresis. A backward shift occurs only if conditions are reversed far enough to reach the other bifurcation point F1. (b) A perturbation (heavy arrow) may also induce a shift to the alternative stable state, provided that it is sufficiently large to bring the system over the border of the attraction basin.
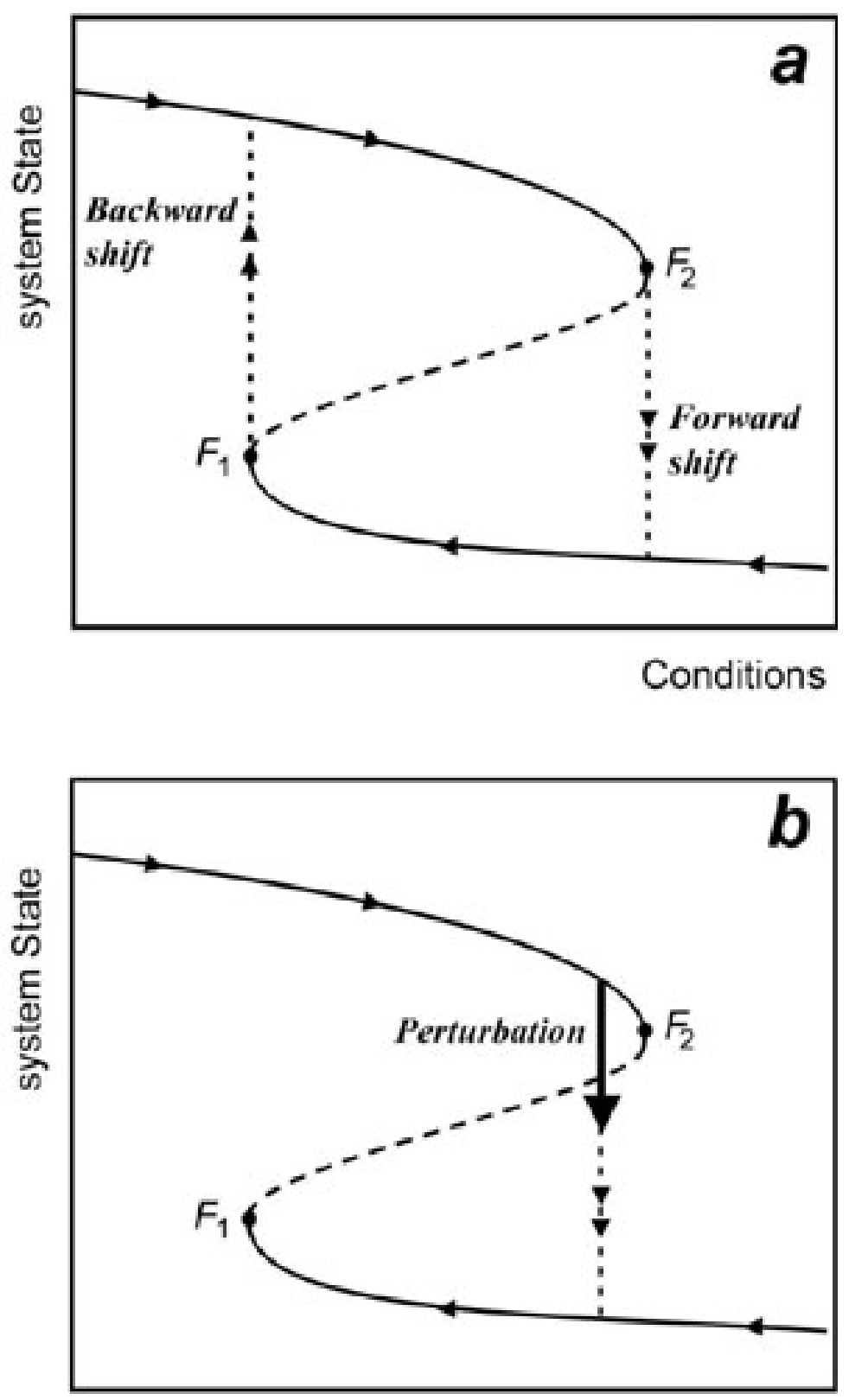

Conditions 
alternative stable state, upside down. Although in such simple examples of systems with alternative stable states, the consequences are intuitively straightforward, the idea is less self-evident with respect to complex systems such as cells, ecosystems, the climate system, and societies. Nonetheless, the concept of alternative stable states, and the resulting possibility of sudden flips from one mode to another, has become the focus of major interest in the study of ecosystem dynamics (Holling 1973, May 1977, Scheffer et al. 2001) and is also the essence of the issue of abrupt climate change (Alley et al. 2003, Taylor 1999).

Here, we review work on how cells, minds, and behavioral patterns can be "locked" into one of several alternative stable modes. It may seem ambitious to bridge this large range of integration levels in one essay. However, we do so because we wish to address the question why "locks" seem so common, even if the associated rigidity that comes with them appears to be a negative thing. We will argue that, especially at physiological levels, such locks usually have an obvious evolutionary advantage, and that this may be true for group behavior too, even though locked attitudes and modes of behavior in individuals and groups can easily lead to undesirable lock-in situations. Rather than using the dynamic systems terminology for alternative attractors, we will use the intuitive term "lock" to refer to a mode that the system does not easily get out of again due to self-stabilizing feedback. We use the term "trap" for a lock with a negative connotation.

\section{CELLS}

On a cellular level, alternative attractors are a common phenomenon. They usually serve a clear purpose. For instance, it is important for cells to "decide" between distinct options over their life cycle. They may, for example, become a liver cell or a blood cell. Not something in between. During early embryonic development, many distinct choices must be made. One of the cases in which positive feedback leading to bistability has been demonstrated is dorsal-ventral patterning (in which the side becomes the back) in fruit flies (Drosophila spp.; Wang and Ferguson 2005). Starting with a shallow gradient of a certain type of protein indicating the position of the back, an intracellular positive feedback circuit amplifies this by promoting future receptor binding as a function of previous signaling strength. The result is the development of an ordered sharp stripe of dorsal cells.

Another example of a cell choice is that of cell suicide through deliberate "programmed cell death." Apoptosis is one of the main types of programmed cell death. This suicide is carried out in an ordered process and serves a clear purpose. For example, the differentiation of human fingers in a developing embryo requires the cells between the fingers to initiate apoptosis so that the fingers can separate. Apoptosis can also occur when a cell is damaged beyond repair or infected with a virus. Such suicide is a distinct choice. The cell must live or die, not something in between. It appears that this all-or-nothing character of apoptosis is realized through positive feedback in a system of signaling proteins (Bagowski and Ferrell 2001), leading to a bistability of the biochemical reaction. More generally, such bistability in cell signaling pathways serves to filter out noise (irrelevant random fluctuations in the environment) and yet allows the cell to respond decisively if stimuli exceed a certain threshold.

\section{INDIVIDUALS}

Human minds are also notorious for locking into one of several contrasting states. Mood swings are one aspect. Depression is a complex phenomenon involving not only the mind, but also overall chemical balances, and feedbacks involving behavioral patterns and social interactions. Whatever the precise mechanisms are, it is well known that unipolar depression can be a quite stable condition. In contrast, individuals with bipolar depression may shift erratically between widely contrasting states of mania and depression.

On a more subtle level, the mind has a tendency to lock into one of several alternative interpretations of reality. A well-known example, drawn from Gestalt psychology, is the human tendency to fit visual cues to search images (Fig. 3). It appears to be difficult to see different interpretations simultaneously, and the resulting "snapping" to one of several alternative interpretations seems to happen on different levels, ranging from interpretation of pictures to more complex theories and world views. Scientists are often faced with this problem in their work as there is "the imminent danger of an unconscious selection and of a 
magnifying of phenomena that fall into harmony with the theory and support it and an unconscious neglect of phenomena that fail of coincidence" (Chamberlin 1897). The same mechanism may play a role in ideology of all kinds, from political to religious beliefs.

One can imagine that the tendency to quickly fit complex observations to search images serves a purpose. It allows efficient recognition of important things, such as food items or dangerous situations. A vivid account of examples of this rapid classification mechanism in humans can be found in the popular book Blink: the Power of Thinking without Thinking, by Malcolm Gladwell (Gladwell 2005). His overview shows that this rapid classification mechanism is much faster and sometimes also more accurate than the parallel and independent rational track that our brain follows. Similar findings have been documented in the study of how experts make rapid decisions (Klein 1999) through pattern recognition, which is much faster than rational process.

Also, behavioral patterns have the tendency to lock into a particular mode, from which it may be difficult to break free. Again, this may often serve a purpose. For instance, when faced with a predator or enemy, your options are either to fight or flee. Once you choose to fight, it makes sense to go for it completely, rather than doubting and wavering between different modes of behavior. Consistency is best. In the case of aggression, a physiological feedback loop has been detected in rats between aggressive behavior and hormonal production. This feedback can ensure that a burst of aggressive behavior typically does not fade away too quickly. It is probably a quite universal mechanism, and you may have noticed this pattern both in children's tantrums and in adult bursts of anger. The aggressive behavior apparently induces a hormonal (adrenocortical) stress response, which in turn promotes a center in the brain to conduct aggressive behavior. This leads to a positive feedback of the controlling mechanisms within the time frame of a single conflict (Kruk et al. 2004). Although this mechanism may contribute to the precipitation and escalation of violent behavior, it can also be seen that a rapid move to a consistent aggressive (or flight) mode of behavior can offer a greater chance of survival than hesitating between different modes of action.
Perhaps the benefits of consistency also explain the curious phenomenon known as the "sunk-cost effect." Economic theory tells us that prior investment should not influence one's consideration of current options. Only the incremental costs and benefits of the current options should influence the decision. However, there are numerous examples suggesting that humans deviate from that rational path and can be trapped into a positive feedback loop between prior investment and behavioral choice. This is called the sunk-cost effect (Arkes and Ayton 1999), but has been referred to in animal research as the Concorde effect (e.g., Dawkins and Carlisle 1976). The dim financial prospects of the Concorde were known long before the plane was completed, but the UK and France decided to continue on the grounds that they had already invested a lot of money. In a review of many studies, Arkes and Ayton (1999) conclude that the Concorde fallacy does not occur in lower animals, but that many studies demonstrate the sunk-cost effect for humans. For example, a study on American basketball players showed that individuals who cost the team more money were given greater playing time regardless of the player's performance (Staw and Hoang 1995). In some cases, on closer look, seemingly irrational sunk-cost behavior may really be explained by the interest of key individuals in maintaining the status quo or in preventing loss of prestige. However, there are also indications that intrinsic psychological mechanisms play a role (Arkes 1996, Arkes and Ayton 1999). Among other things, self-justification (Brockner 1992) may play a role, as people often do not like to admit that their past decisions were incorrect. In fact, studies of conversion and brainwashing suggest that beliefs can be an essential part of identity, explaining the large resistance of individuals to such turnover (Gerlach and Hine 1970). Whatever the explanation is, adult humans apparently have a tendency to stick to a certain mode of behavior even if it is rationally a bad choice. This lock-in mechanism, caused by apparent self-reinforcing adherence to a mode of behavior, tends to promote inertia, a lack of responsiveness to changes in the environment.

\section{GROUPS}

Whereas individuals have a tendency to lock into one particular interpretation or behavior, group dynamics add a second level of inertia. We have a strong tendency to lock into the same world view, 
Fig. 3. Interpretation of images is notoriously ambiguous. You can imagine the marked corner in the Necker cube to be at the front side or at the back side. Once you see one interpretation, shifting to the other one is not easy.



and more generally, to the same behavior and fashions as our peers. This mechanism can cause inertia and shifts in opinions and behavior on massive scales, as can be demonstrated well by a simple mathematical model (Scheffer et al. 2003) assuming that, for each individual, there are two modes of "opinion" (or attitude) with respect to the question of whether action should be taken against a problem: passive or active. Individuals adopt an attitude depending on their perception of how serious the problem is, and how effective it would be to push for regulation. However, their attitude is also affected by peer group "social pressure." Individuals are assumed to adopt an attitude through a cost-benefit argument, assuming a cost of deviating from the overall group tendency (going against peer pressure) and a perceived net utility of adopting the positive attitude. The predictions of such a model are that most individuals favor a passive attitude until a critical point is reached at which a sudden and fast transition to an active attitude toward combatting the problem occurs (Fig. 4). This dynamic is not unlike the "paradigm shifts" described by Kuhn (1962), where the accumulation of scientific anomalies in data collected using one perspective or set of assumptions results in a sudden and radical shift in scientific perspectives and the birth of a new theory that "explains" the anomalies (Brock and Durlauf 1999).

Indeed, many studies confirm that public attitude often exhibits sudden rather than gradual shifts (Gladwell 2000). We cannot conduct controlled experiments to unravel the mechanisms on the scale of large groups or entire societies. However, experiments in small groups nicely reveal the likely basic mechanism. For instance, early studies in experimental psychology have shown that people's response to calls for help in emergency situations depends very much on how they read the response 
Fig. 4. In societies with little difference among individuals and high peer pressure, the response of public attitude to an increase in perceived problem size is predicted to be discontinuous. When the problem is perceived to be small (and the perceived pay-off of taking action is low), the attitude of most individuals is passive with respect to the problem. Society abruptly shifts to a predominantly active attitude (creating political pressure to regulate the problem) when the perceived severity of the problem has grown sufficiently to reach a critical point $(\mathrm{F} 1)$. If, subsequently, the severity of the problem is reduced, the active attitude toward regulation remains until another critical threshold point (F2) is reached where an equally abrupt transition to a passive attitude occurs. (From Scheffer et al. 2003.)

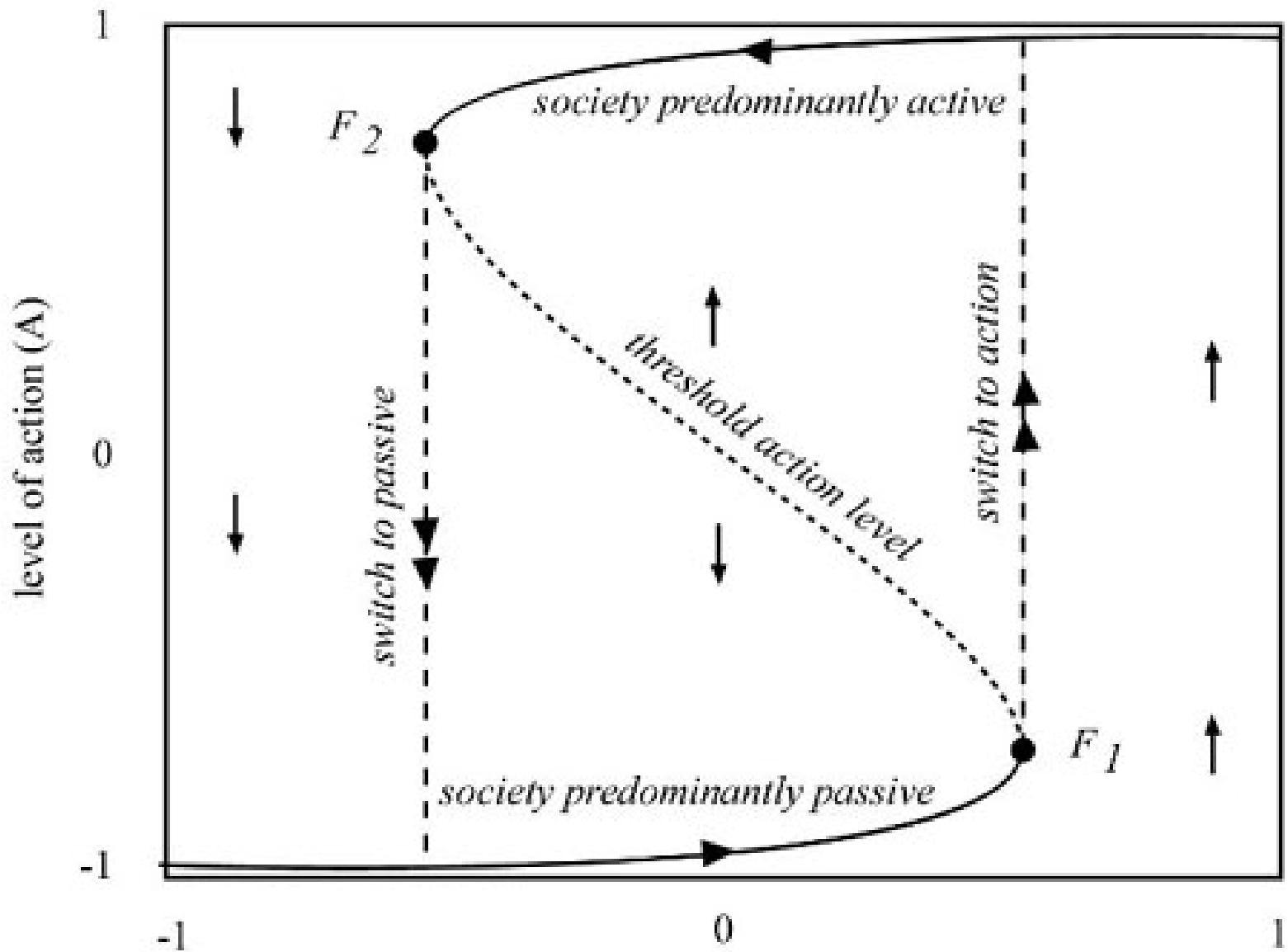

\section{Perceived pay-off of taking action (h)}

of those around them (Darley and Latane 1968). If nobody in a group of bystanders acts to help, you are likely to copy that behavior. As a result, groups have a tendency to remain locked into a passive attitude, whereas individuals would already have acted. In hindsight, there is often disbelief in this dynamic. "How is it possible that so many stood by and did nothing?" Ironically, the truth is that it may often be due to rather than despite of the fact that so many stood by.
The tendency to lock into the same attitude implies that groups may often be rigid when it comes to responding to changing conditions. Even if there is a general feeling that something needs to be done, it can be surprisingly hard to get a group out of the gridlock. In such situations, the "exceptional few" play an important role in catalyzing tipping points. Some individuals appear to be able to mobilize groups to change due to a combination of factors. For instance, they may be particularly well 
connected (Milgram 1967), have high social capital, be innovators or early adopters by nature (Rogers 1983), or have the charisma to cause emotional contagion (Hatfield et al. 1994). The absence of such leaders will make a social group as a whole rigid and weak when adaptation to change is required.

In summary, evidence scattered across the literature suggests that peers in a group have a tendency to become locked into the same set of attitudes and behavioral patterns. This mutual contagion mechanism causes inertia, making it more difficult to respond to new situations, especially if the complexity of the situation is such that it is not easy to see what the problem really is and how it might be solved. Opinion leaders are highly important in breaking free of such a non-adaptive gridlock. This implies chances for innovation and manipulation alike. History provides a wealth of examples, ranging from Gandhi to Hitler, that illustrate how, in situations of crisis, the niche for sense making can be filled in very different ways, and the outcome depends very much on who among the "exceptional few" will catalyze new attitudes.

\section{RIGIDITY AND THE COLLAPSE OF ANCIENT SOCIETIES}

Could the tendency to lock into a rigid group mode of behavior also limit innovation at a societal level if a crisis were to arise? Surely, the future will be challenging in that sense for mankind in view of the current level of resource depletion and the expected trends in climate, wealth, and population densities. One way to get an idea of how societies may respond to major crises in the future is to look at historical cases. Obviously, mankind has come a long way and countless problems have been overcome. Although this should encourage trust in our ability to solve future problems, several cases of dramatic failure stand out that are worth exploring as they may give some insight into fundamental caveats of the path to adequate societal response to crisis.

Perhaps the best known class of failures is the collapse of many advanced ancient civilizations when faced with a resource crisis (Diamond 2004). Clearly, history will not just repeat itself, as we live in a very different world now in many respects. For instance, local resource scarcity can be resolved by transportation, and technological solutions can greatly enhance resource use efficiency and productivity. However, the historical cases suggest some fundamental characteristics of societal response to problems that are deeply rooted in human nature, as revealed by studies of modern human behavior. The main pattern we wish to stress here is the tendency to become increasingly rigid and to adhere to old structures and habits as a sense of crisis increases. Evidence suggests that this may reduce the chance for innovative solutions and much needed change in behavioral patterns.

Perhaps the most striking aspect in the puzzle of the apparent collapse of many ancient civilizations is the power, wealth, and sophistication suggested by the impressive structures they left behind. How is it possible that the same societies that built such structures were unable to avoid falling into the trap that led to complete collapse? Remarkably, there is some evidence suggesting that the inertia in the face of trouble was due to (rather than despite) the elaborate cities and temples built. For instance, archeological reconstructions have revealed that the Anasazi in the American Southwest kept constructing their big cities even during severe periods of droughts, whereas in small settlements in the same region construction was abandoned during such adverse episodes (Janssen et al. 2003). This fits with the idea that the "sunk-cost effect" discussed earlier may have contributed to the apparent inability to respond to crisis in a flexible way. In a resource crisis, such a tendency may have made it more difficult for ancient societies to emigrate away from structures in which much had been invested in time to prevent catastrophic collapse (Janssen et al. 2003).

In this case, the sunk-cost effect refers to rigidity due to over-valuation of established material goods. However, there is a much broader tendency to cling to world views and existing ways of living as a crisis looms. The fate of the Vikings who colonized Greenland is a stunning example of such an apparent lack of flexibility (Diamond 2004). These "Norse" chose to raise the same domestic livestock that they were used to in their homeland, even though the climate of Greenland was really too harsh for these types of animals. Because of the climate, cows had to be kept inside for most of the year, and excavated skeletons show that they did not grow very large, probably because of the poor diet. The Norse used meat of wild animals, such as caribou and seals, to supplement their diet. However, they ran into serious trouble when the climate plunged into an extensive cold period, known as the "Little Ice Age," in the early 1400s. The Greenland Norse died 
out, and their remains suggest that famine was the chief problem. Although this may seem explainable in light of the extreme climatic conditions, the puzzling thing is that contemporary Inuit who were their neighbors survived. This is probably because the Inuit possessed superior indigenous techniques, especially for hunting seals. The Greenland Norse never copied these techniques, even though they lived side by side with the Inuit for centuries. Rather they clung to their old ways of living. As a result, they starved in the presence of abundant unutilized food resources. Although the story of the Greenland Norse is only one example, and might be interpreted in alternative ways (e.g., see Wikipedia updates on theories), it seems that the tendency to hold stubbornly to habits that led to great success in the past has led numerous societies into trouble over history (Diamond 2004). On a smaller scale, precisely the same dynamics can be observed in companies that "oversimplify" and cling to a narrow set of behaviors that have brought past success (Miller 1993).

\section{ZOOMING IN ON THE PARADOX: THE EFFICIENCY TRAP}

Our brief overview so far suggests that, on the cellular level and in individual minds, the benefits of locking into one of several alternative stable modes are often clear. However, the benefits of locking into a rigid pattern in society are less obvious. Indeed, it seems that locks frequently turn into non-adaptive traps, and one wonders why rigidity in societies, groups, or businesses can be so dominant. After all, the benefits of more adaptive dynamics seem self-evident. Who would deny that critical attitudes and innovative ideas should be always embraced? Nevertheless, reality is different.

Consider the experiment (Boulding 1964) in which groups had to complete complex assignments. In half the groups, the experimenters introduced a "plant," someone trained by the experimenter to take a critical attitude ("devil's advocate") in reference to group decisions. The groups with the plants consistently outperformed those without the plants, reinforcing the idea that conflict (within limits) plays an important role in problem solving. Nevertheless, in the second round of the experiment, when all groups were asked in a secret ballot to eliminate one team member in order to improve performance, all groups who had devil's advocates chose to eliminate them, thus eliminating their competitive advantage. Apparently, few groups recognize the value of diversity and conflict in group problem solving. Is this silly, or might there generally be an advantage to coherent groups dancing to the same beat?

Glancing over different fields of research, it seems almost as if there is a fundamental trade-off between two clusters of properties that we could broadly label as "explorative" vs. "efficient" (or "exploitative"). In animal studies, such contrasting behavioral syndromes have long been known (Koolhaas et al. 1999, Sih et al. 2004). However, the trade-off between exploration and exploitation has also been studied extensively in management science, where it has significant implications for the way companies are run (Levinthal and March 1993, March 1994). Small innovative companies create new products; to bring them to market, however, they must be launched and reliably produced within reasonable time and cost parameters. This requires increasing efficiency and precision. Waste must be kept at a minimum, volume increased, and price reduced if a competitive advantage is to be maintained. The exploration and exploitation phases require radically different modes of thinking and acting, indeed they require two different organizational cultures (Perrow 1973). This in part explains the challenge of continuous innovation: it is clearly hard to simultaneously orchestrate the dynamics of exploration and exploitation. So, what to do? Successful large and long-lived companies that depend on continuous innovation, such as Phillips or IBM, have addressed this tension by "encapsulating" creative or explorative units. They often physically separate the research and development departments or teams from the production teams, and train special managers who can champion and shepherd the innovation process while buffering it from the demands of production. This allows the company to build up a bank of new ideas and products to draw upon in future launches, while simultaneously going to scale in producing and marketing successful initiatives (Kidder 1981, Kanter 1985, Quinn 1985). Others spin off the ideas when they are successful enough, thereby avoiding having to divert energy from creativity to production (Mintzberg and Westley 1992).

All this suggests that a compromise between the explorative and the efficient mode is typically avoided, and therefore, is probably a bad idea in general. It would appear that even minimal amounts of exploration will harm efficiency. One could 
speculate that this is an underlying reason why, in most cases, it may simply feel best for group survival and well-being if all members are in sync and pursuing similar behaviors. Although this may often be functional for the group, it may also severely limit the adaptive capacity. A striking example is the behavior of groups under siege. In his study of the Bay of Pigs crisis, in which President John F. Kennedy and his group of decision makers made disastrous choices in the interests of group solidarity, Janis (1972) coined the now famous term "group think" to describe the propensity of groups that require new thinking to deal with a crisis to voluntarily abandon their capacity for problem solving in order to maintain group cohesion. Another example is given in the book "When Prophecy Fails" (Festinger et al. 1956), which explores the reactions of a millennial cult that had predicted that the world would end on a certain date and had retreated to a sanctuary to await this momentous occurrence. When the day came and went without the anticipated apocalypse, instead of questioning their prophecy, the group became even more withdrawn and rigid in their thinking.

The tendency to lock into an efficient but nonexplorative mode during times of stress implies the risk of a trap. Let us call it the "Efficiency Trap." It limits the chances of escaping from a crisis through innovative shifts in strategy. One way of depicting these dynamics is to imagine that, in an explorative phase, individuals, groups, or businesses look for an optimum in the "fitness landscape" (Fig. 5). Subsequently, they specialize to become more efficient, improving their particular spot in the fitness landscape further. However, this comes at the cost of their explorative capacity to scan the landscape for alternative good places. This becomes a problem if the landscape gradually changes, causing the originally good spot to end up in a valley of bad fitness. The resulting experienced stress entails further local adaptation, thus improving the local fitness peak slightly, but also increasing myopia and rigidity further.

\section{REMAINING ADAPTIVE WHEN WE ARE HARDWIRED TO BE CONSISTENT}

In summary, our review suggests that the evolutionarily important capacity to lock into consistent modes of behavior is deeply rooted. Although it has great advantages, it may also turn into a pathological pattern in human societies if it leads to excessive rigidity in a changing world. Of course, our greatest advantage is that we can analyze such patterns and learn from them. As we have seen, big businesses have learned to foster innovation with much success. Also, numerous great social innovations have occurred. For instance, the 2006 Nobel Peace Prize was awarded to Muhammad Yunus, a Bangladeshi economist, for sparking a worldwide microcredit movement: loaning poor people small amounts of money so that they can start or improve their tiny businesses and escape from the poverty trap. Indeed, we have learned a lot, and we keep on innovating, so it would be foolish to think that we would be as rigid as the Greenland Norse if it came to adjusting our ways of living in the face of a crisis. However, it is hard to deny that societies today remain notoriously slow when responding to new problems (Scheffer et al. 2003). If we are faced with runaway climate change or if resource crises deepen, will we be innovative enough to find a way out, and flexible enough to adjust our patterns of living? Maybe so, but as we have seen there are also indications that rigidity in groups sometimes increases in a crisis, and smart "integrated solutions" may become increasingly unlikely in situations of stress. The dynamics of societal response to problems are obviously driven by a complex set of factors. However, even on this large scale, similar patterns can be seen, as has been shown for small groups. For instance, people in nations that live under more stressful conditions (e. g., because of poverty or social crisis) exhibit a pattern of increasing dependence on group norms and authority, and a decreasing dependency on rationality and individual choice, as a basis for making decisions (Inglehart and Baker 2000). Clearly, it is rather speculative to extrapolate any such pattern into the future of our societies. However, altogether, the evidence suggests that, as future resource or climatic crises become severe on a global scale, there is a risk that the resulting stress may tend to result in an even more rigid adherence to old patterns. Books have been written about future scenarios, and we will not recapitulate the elaborate visions on numerous aspects and risks here. Nonetheless, understanding the mechanisms of inertia is clearly relevant when it comes to developing new strategies to reduce the risk of future crisis. Our review suggests that rigidity is so deeply rooted because it evolved as a way to ensure consistency, which is important to achieve efficient functioning on levels varying from the cell to individuals and groups. 
Fig. 5. Cartoon of the efficiency trap. If exploration has revealed an optimum in the fitness landscape (panel a), a person, group, or company may shift to an exploitative mode where improved efficiency and specialization enhances the fitness further (panel b). However, in such a behavioral mode, the explorative capacity to scan for alternative options is reduced. This implies the risk of becoming trapped in a situation that may seem optimal from a myopic view, but is suboptimal compared with potentially much better places in the changing fitness landscape (panel c).
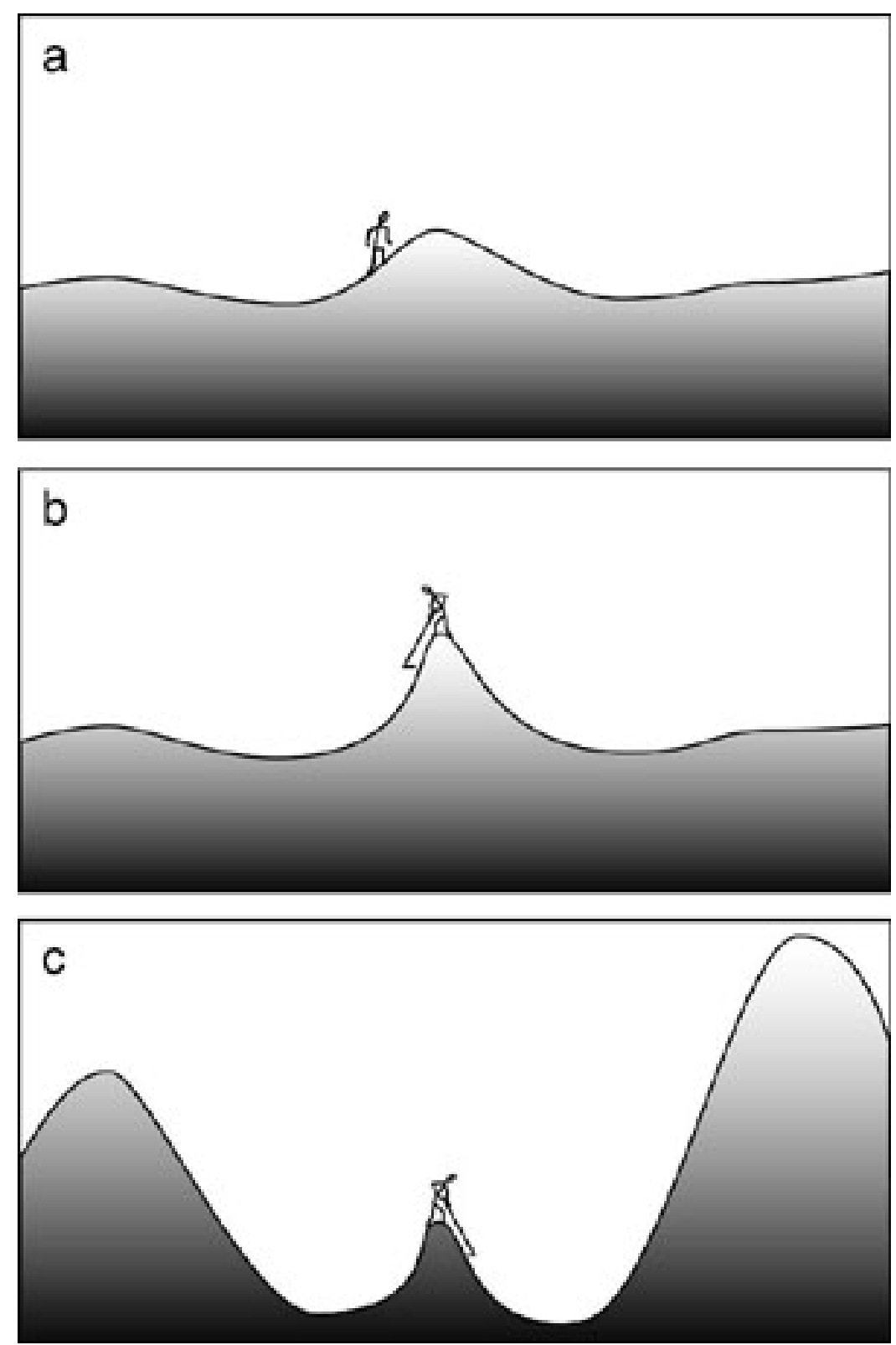
Responses to this article can be read online at:

http://www.ecologyandsociety.org/vol12/iss2/art36/responses/

\section{Acknowledgments:}

We thank William (Buz) Brock for numerous insightful comments, the Resilience Alliance for facilitating this interdisciplinary work, and two anonymous reviewers for help in clarifying the focus.

\section{LITERATURE CITED}

Alley, R. B., J. Marotzke, W. D. Nordhaus, J. T. Overpeck, D. M. Peteet, R. A. Pielke, R. T. Pierrehumbert, P. B. Rhines, T. F. Stocker, L. D. Talley, and J. M. Wallace. 2003. Abrupt climate change. Science 299:2005-2010.

Arkes, H. R. 1996. The psychology of waste. Journal of Behavioral Decision Making 9:213-224.

Arkes, H. R., and P. Ayton. 1999. The sunk cost and Concorde effects: are humans less rational than lower animals? Psychological Bulletin 125:591600 .

Bagowski, C. P., and J. E. Ferrell. 2001. Bistabillity in the JNK cascade. Current Biology 11:1176-1182.

Boulding, E. 1964. Power and conflict in organizations. Further reflections on conflict management. Pages 146-150 in R. L. Kahn and E. Boulding, editors. Power and conflict in organizations. Basic Books, New York, New York, USA.

Brock, W., and S. Durlauf. 1999. A formal model of theory choice in science. Economic Theory 14:113-130.

Brockner, J. 1992. The escalation of commitment to a failing course of action-toward theoretical progress. Academy of Management Review 17:3961.

Chamberlin, T. C. 1897 . The method of multiple working hypotheses. Journal of Geology 5:837848.
Darley, J., and B. Latane. 1968. Bystander intervention in emergencies: diffusion of responsibility. Journal of Personality and Social Psychology 8:377-383.

Dawkins, R., and T. R. Carlisle. 1976. Parental investment, mate desertion and a fallacy. Nature 262:131-133.

Diamond, J. 2004. Collapse: how societies choose to fail or survive. Viking Books, New York, New York, USA.

Festinger, L., H. W. Riecken, and S. Schachter. 1956. When prophecy fails. Harper and Row, New York, New York, USA.

Gerlach, L. P., and V. H. Hine. 1970. People, power, change: movements of social transformation. Bobbs-Merrill, Indianapolis, Indiana, USA.

Gladwell, M. 2005. Blink: the power of thinking without thinking. Little, Brown and Co., Boston, Massachusetts, USA.

Hatfield, E., J. Copioppo, and R. Rapson. 1994. Emotional contagion. Cambridge University Press, Cambridge, UK.

Holling, C. S. 1973. Resilience and stability of ecological systems. Annual Review of Ecology and Systematics 4:1-23.

Inglehart, R., and W. E. Baker. 2000. Modernization, cultural change, and the persistence of traditional values. American Sociological Review 65:19-51.

Janis, I. L. 1972. Victims of groupthink: a psychological study of foreign-policy decisions and fiascoes. Houghton-Mifflin, New York, New York, USA.

Janssen, M. A., T. A. Kohler, and M. Scheffer. 2003. Sunk-cost effects and vulnerability to collapse in ancient societies. Current Anthropology 44:722-728.

Kanter, R. M. 1985. The change masters. Free Press, New York, New York, USA.

Kidder, J. T. 1981. The soul of a new machine. Little, Brown, Boston, Massachusetts, USA. 
Klein, G. 1999. Sources of power. MIT Press, Boston, Massachusetts, USA.

Koolhaas, J. M., S. M. Korte, S. F. de Boer, B. J. van der Vegt, C. G. van Reenen, H. Hopster, I. C. de Jong, M. A. W. Ruis, and H. J. Blokhuis. 1999. Coping styles in animals: current status in behavior and stress-physiology. Neuroscience and Biobehavioral Reviews 23:925-935.

Kruk, M. R., J. Halasz, W. Meelis, and J. Haller. 2004. Fast positive feedback between the adrenocortical stress response and a brain mechanism involved in aggressive behavior. Behavioral Neuroscience 118:1062-1070.

Kuhn, T. 1962. The structure of scientific revolution. University of Chicago, Chicago, Illinois, USA.

Levinthal, D. A., and J. G. March. 1993. The myopia of learning. Strategic Management Journal 14:95-112.

March, J. 1994. Primer on decision making: how decisions happen. Free Press, New York, New York, USA.

May, R. M. 1977. Thresholds and breakpoints in ecosystems with a multiplicity of stable states. Nature 269:471-477.

Milgram, S. 1967. The small world problem. Psychology Today 1:60-67.

Miller, D. 1993. The architecture of simplicity. Academy Of Management Review 18:116-138.

Mintzberg, H., and F. Westley. 1992. Cycles of organizational-change. Strategic Management Journal 13:39-59.

Perrow, C. 1973. Short and glorious history of organizational theory. Organizational Dynamics 2:2-15.

Quinn, B. 1985. Managing innovation: controlled chaos. Harvard Business Review May-June:73-84.

Rogers, E. M. 1983. Diffusion of innovations. Free Press, New York, New York, USA.

Scheffer, M., S. R. Carpenter, J. A. Foley, C. Folke, and B. Walker. 2001. Catastrophic shifts in ecosystems. Nature 413:591-596.
Scheffer, M., F. Westley, and W. Brock. 2003. Slow response of societies to new problems: causes and costs. Ecosystems 6:493-502.

Sih, A., A. Bell, and J. C. Johnson. 2004. Behavioral syndromes: an ecological and evolutionary overview. Trends in Ecology and Evolution 19:372-378.

Staw, B. M., and H. Hoang. 1995. Sunk costs In the NBA - why draft order affects playing time and survival In professional basketball. Administrative Science Quarterly 40:474-494.

Strogatz, S. H. 1994. Nonlinear dynamics and chaos-with applications to physics, biology, chemistry and engineering. Westview Press, Boulder, Colorado, USA.

Taylor, K. 1999. Rapid climate change. American Scientist 87:320-327.

Wang, Y. C., and E. L. Ferguson. 2005. Spatial bistability of DPP-receptor interactions during Drosophila dorsal-ventral patterning. Nature 434:229-234. 